\title{
Differences in Survival Rates between Different Patterns of Unstable Pertrochanteric Femoral Fractures*
}

\author{
Amir Herman ${ }^{1,2 \#}$, Yair Landau ${ }^{1}$, Alexander Hazanov ${ }^{3}$, Tal Segev ${ }^{4,5}$, Ran Thein ${ }^{1}$, Nachshon Shazar ${ }^{1}$ \\ ${ }^{1}$ Department of Orthopedic Surgery, Chaim Sheba Medical Center, Tel-Hashomer, Israel; ${ }^{2}$ Talpiot Medical Leadership Program, \\ Chaim Sheba Medical Center, Tel-Hashomer, Israel; ${ }^{3}$ Department of Anesthesiology, Chaim Sheba Medical Center, Tel-Hashomer, \\ Israel; ${ }^{4}$ Department of Vascular Surgery, Chaim Sheba Medical Center, Tel-Hashomer, Israel; ${ }^{5}$ Sackler Faculty of Medicine, Tel \\ Aviv University, Tel Aviv, Israel. \\ Email: \#amirherm@gmail.com
}

Received August $6^{\text {th }}, 2013$; revised September $6^{\text {th }}, 2013$; accepted September $21^{\text {st }}, 2013$

Copyright (C) 2013 Amir Herman et al. This is an open access article distributed under the Creative Commons Attribution License, which permits unrestricted use, distribution, and reproduction in any medium, provided the original work is properly cited.

\begin{abstract}
Background: Unstable pertrochanter femur fractures are common in orthopedic practice. They pose a surgical challenge in both reduction and fixation. The fixation devices used are based on hip intramedullary nailing with femur head lag screw or blade. The aim of this paper is to compare different types of unstable pertrochanter fractures. Materials \& Methods: We retrospectively reviewed 386 unstable pertrochanter femur fractures surgically treated in our hospital from 2000 to 2009 . These included $62(16.1 \%)$ unstable pertrochanter fractures with fractured lesser trochanter (31.A2-2, 31.A2-3); 63 (16.3\%) reverse oblique fractures (31.A3-1), 51 (13.2\%) transverse fractures (31.A3-2), 145 $(37.6 \%)$ comminuted fractures (31.A3-3) and $65(16.8 \%)$ subtrochanter fractures. We compared survival rates between fracture types. The clinical characteristics, surgery immediate outcome (e.g., tip apex distance, reduction quality), and long term results, i.e., complications were also compared between fracture types. Results: Survival analysis showed that the fracture types can be grouped into low and high risk fracture types. The former group included, reverse oblique and comminuted fractures. Lesser trochanter, transverse and subtrochanter fractures were included in the high risk group. The survival estimates for five years were $64.6 \%$ and $49.3 \%$ for the low and high risk fracture types, respectively ( $\mathrm{p}$ value $=0.008)$. Multivariate survival analysis showed that the hazard ratio for the high risk fracture group was 1.9 $(95 \% \mathrm{CI}=1.37-2.67)$. No differences were found between unstable pertrochanter femur fractures with regards to clinical and epidemiology characteristics. Optimal tip apex distance (TAD) of less than $25 \mathrm{~mm}$ was found in $66.7 \%$, $57.1 \%$ and $66.7 \%$ of lesser trochanter, reverse oblique and sutrochanter fractures, respectively. TAD of less than $25 \mathrm{~mm}$ was found in $81.2 \%$ of both transverse and comminuted fractures ( $\mathrm{p}$ value $=0.032$ ). No statistically significant difference was found between fracture types, in regards to complication or revision rates. Conclusions: Survival rates were higher in patients suffering from reverse oblique or comminuted pertrochanteric fractures. No differences were found between fracture types, in regards to clinical and other outcome parameters.
\end{abstract}

Keywords: Intertrochanteric Fractures; Survival; Fracture Classification

\section{Introduction}

Pertrochanteric fractures are among the most widely treated orthopedic injuries. Their annual incidence is expected to reach 500,000 by 2040 , in the US alone [1]. About half of this is estimated to be unstable factures [2].

The AO/OTA classification system divides pertrochanteric fractures into several groups: simple pertrochanteric

\footnotetext{
*Conflict of interest statement: No benefit in any form has been or will be received from a commercial party related directly or indirectly to the subject of this manuscript.

${ }^{\#}$ Corresponding author.
}

(31.A1), pertrochanteric with lesser trochanter fracture (31.A2) and complex pertrochanteric fractures (31.A3) [3]. Each of these three groups is further divided into three groups, consisting of a total of nine different fracture patterns. These patterns are commonly divided into stable pertrochanteric fractures (31.A1 fracture group and 31.A21 subtype) and unstable pertrochanteric fractures (31.A22 and 31.A2-3 subtypes and 31.A3 fracture group) [4-6]. Fixation devices available for pertrochanteric fractures vary from intra-medullary devices and extra-medullary plate both with femur head screw. The extra-medullary 
device was shown to have fewer complications in stable pertrochanteric fractures. Patients with unstable pertrochanteric fractures were shown to benefit from intramedullary fixation devices such as the Cephalomedullary nail, Gamma nail, Y nail among other [5,7-20].

Subtrochanteric fractures are defined as fractures within the immediate $5 \mathrm{~cm}$ distal to the lesser trochanter. As opposed to femur shaft fractures, these fractures require fixation of the femoral head-neck-shaft complex. Fractures of the subtrochanteric region often are fixed by intramedulary proximal femur fixation devices. As such these factures can be included as part of the unstable persubtrochanteric fracture patterns [21].

Several authors described their experience of different unstable pertrochanteric fractures. These include a recent review by Lundy focusing on subtrochanteric fractures and a description of open reduction in treating subtrochanteric fractures [2]. Other authors focused on reverse oblique or transverse fracture types [6]. We are unaware of any work comparing the survival among different subtypes of unstable pertrochanteric fractures.

In this report we compare between the different patterns of unstable per-subtrochanteric fractures. We compare the survival rates, epidemiology, reduction achieved, screw placement, complications and revision rates between the different fracture types.

\section{Patients \& Methods}

The study presented is a retrospective study based on national mortality registry and our hospital admission and outpatient-clinic files. The study was approved by our institute's internal review board (IRB) ethics committee. Since this is a retrospective study, patients' informed consent was not required by the IRB.

Between 2000 and 2009, 386 unstable pertrochanteric fractures were operated in our institute. These consisted of $62(16.1 \%)$ pertrochanteric fractures in which the lesser trochanter was fractured and the fracture was defined as unstable (31.A2-2 and 31.A2-3). There were 63 (16.3\%) reverse oblique fractures (31.A3-1), 51 (13.2\%) transveres pertrochanteric fractures (31.A3-2) and 145 (37.6\%) of comminuted fractures (31.A3-3). Subtrochanteric fractures included $65(16.8 \%)$ fractures.

The Fractures had been fixed by means of the Targon proximal femur (Targon PF) device (Aesculap, Tuttlingen, Germany) or with the antirotation trochanteric nailing system (ATN) device (dePuy, Warsaw, IN, USA). Both of which are double screw intramedullary fixation devices. All surgeries were performed in accordance to standard surgery technique and the manufacturer's recommendations.

The radiology computerized achieve was used for classification of fractures according to the OTA/AO classifi- cation system [3]. Patterns were classified by two independent researchers (A.O and Y.L). The senior author (N.S) was consulted whenever consensus was not reached. Radiology measurements were performed including the tip apex distance and placement of the center of the lag screw within the head-neck interface "Safe-zone" (defined as the second quarter from the bottom) [22].

Acceptable reduction was considered as translation of less than $20 \mathrm{~mm}$ in any plane as measured by the medial cortex in anterior-posterior radiography view or anterior cortex on axial radiography view.

Statistical analysis was performed by an experienced biostatistician (A.H.). Data analysis was conducted using SPSS $\odot 16$ (SPSS $\odot$, Chicago, IL). Categorical data are presented as frequency count (percent of available data). Comparisons of categorical variables between fracture types were performed using either the chi-square test or the Fisher's exact test. The latter was used when expected count in any cell was less or equal five. Continuous variables are presented as mean ( \pm standard deviation). Comparisons of continuous variables among fracture patterns were performed using the Kruskal-Wallis test. Comparisons of paired data, mainly the increase in mobility aids before and one year after surgery, were performed using the Wilcoxon rank sign test. Survival data are presented using the Kaplan-Meier survival curves. KaplanMeier survival estimates were used for one and five years survival along with $95 \%$ confidence interval $(95 \% \mathrm{CI})$. Comparisons between survival curves were done by the log-rank test.

Data were extracted by reviewing of the patients' admission and out-patients clinic electronic files. Complications, comorbidities, use of walking aids and recovery parameters were extracted from the hospital records. The national mortality registry was consulted for mortality status and date. Patients that were not registered as deceased were considered as censured at the date of the inquiry.

Multivariate survival analysis was performed with the Cox proportional hazards model. The independent covariates in the model were fracture group (according to high or low risk fracture type), ASA score and Age group —up to 60 years old (46 pts, 11.9\%), 60 - 80 years old (158 pts, $40.7 \%$ ), above 80 year old (182 pts, $47.1 \%$ ). Results are reported as hazard ratios and their $95 \%$ confidence intervals. Hazard ratio should be interpreted as relative risk, so that hazard ratio above one means excessive risk.

Data were not available for all patients in all variables measured. The numbers of patients used for analysis of each variable are given within the summary tables. In each analysis frequencies and percents were calculated from available data. For example, for epidemiologic and clinical presentation parameters, percents were calculated from 
the entire patients' population. Complications and revision rates are calculated from a subset of patients which included patients that either had a complication or completed at least one year of follow-up and showed signs of union on X-ray radiography.

\section{Results}

Between 2000 and 2009, 386 unstable pertrochanteric fractures were operated in our institute. These included $95(24.6 \%)$ fractures in men and 291 (75.4\%) fractures in women. Mean age at surgery was 76.16 years $( \pm 15.2)$. Mean American society of anesthesiologists (ASA) score was $2.75( \pm 0.61)$, where 124 patients $(32.2 \%)$ and 225 patients $(58.4 \%)$ had ASA scores of 2 and 3, respectively. Patients with transverse fractures (31.A3-2) had higher ASA scores $(p$ value $=0.026)$. Mechanism of injury was low energy fall in 175 fractures $(87.1 \%)$. Initial treatment at the emergency ward included skeletal traction in 145 fractures $(71.8 \%)$. Skeletal traction was performed more often in reverse oblique, comminuted or subtrochanter fractures. This difference was found to be statistically significant $(p$ value $=0.001)$ Epidemiological and clinical data according to fracture types are presented in Table 1.

Of the 386 fractures treated, 254 fractures (65.8\%) were treated by the Targon PF (C) device, while 132 fractures $(34.3 \%)$ were fixed using the ATN (C) device. No statistically significant difference was found between the fracture types. The nail length was found to be longer (300 mm - $340 \mathrm{~mm}$ ) in fixation of subtrochanteric and comminuted fractures (Table 2).

Immediate surgical outcome varied between fracture types. Tip Apex Distance (TAD) was found to be below $25 \mathrm{~mm}$ in about $81 \%$ of comminuted and transverse frac-

Table 1. Demographic and clinical characteristics (Total $=386$ patients).

\begin{tabular}{|c|c|c|c|c|c|c|}
\hline & $\begin{array}{c}\text { Fractured Lesser } \\
\text { Trochanter } \\
(\mathrm{A} 2.2 \& \mathrm{~A} 2.3) \mathrm{N}=62\end{array}$ & $\begin{array}{l}\text { Reverse Oblique } \\
\text { (A3.1) } \mathrm{N}=63\end{array}$ & $\begin{array}{c}\text { Transverse } \\
\text { (A3.2) } \mathrm{N}=51\end{array}$ & $\begin{array}{c}\text { Comminuted } \\
\text { (A3.3) } \mathrm{N}=145\end{array}$ & $\begin{array}{l}\text { Subtrochanteric } \\
\qquad N=65\end{array}$ & $P$ value \\
\hline \multicolumn{7}{|l|}{ Gender } \\
\hline Male & $20(32.3 \%)$ & $11(17.5 \%)$ & $9(17.6 \%)$ & $35(24.1 \%)$ & $20(30 \%)$ & \\
\hline Female & $42(67.7 \%)$ & $52(82.5 \%)$ & $42(82.4 \%)$ & $110(75.9 \%)$ & $45(69.2 \%)$ & 0.173 \\
\hline Age & $78.9( \pm 12.5)$ & $79.0( \pm 9.8)$ & $77.5( \pm 14.2)$ & $75.8( \pm 14.8)$ & $70.4( \pm 21.1)$ & 0.243 \\
\hline \multicolumn{7}{|l|}{ Side } \\
\hline Left & $32(51.6 \%)$ & $32(50.8 \%)$ & $29(56.9 \%)$ & $78(53.8 \%)$ & $34(52.3 \%)$ & \\
\hline Right & $30(48.4 \%)$ & $31(49.2 \%)$ & $22(43.1 \%)$ & $67(46.2 \%)$ & $31(47.7 \%)$ & 0.971 \\
\hline ASA score & $2.69( \pm 0.64)$ & $2.78( \pm 0.60)$ & $3.00( \pm 0.566)$ & $2.68( \pm 0.61)$ & $2.72( \pm 0.50)$ & 0.026 \\
\hline Above one year follow-up & $26(41.9 \%)$ & $26(41.3 \%)$ & $19(37.3 \%)$ & $72(49.7 \%)$ & $22(34.4 \%)$ & 0.253 \\
\hline Skeletal traction $(\mathrm{N}=202)$ & $3(7 \%)$ & $11(40.7 \%)$ & $5(17.9 \%)$ & $25(32.9 \%)$ & $13(46.4 \%)$ & 0.001 \\
\hline Diabetes Mellitus $(\mathrm{N}=201)$ & $10(23.8 \%)$ & $4(14.8 \%)$ & $5(17.9 \%)$ & $19(25.0 \%)$ & $5(17.9 \%)$ & 0.764 \\
\hline \multicolumn{7}{|l|}{$\begin{array}{l}\text { Mechanism of injury } \\
(\mathrm{N}=202)\end{array}$} \\
\hline Low energy (fall) & $37(86 \%)$ & $25(92.6 \%)$ & $24(85.7 \%)$ & $68(89.5 \%)$ & $21(77.8 \%)$ & \\
\hline High energy & $6(14 \%)$ & $2(7.4 \%)$ & $4(14.3 \%)$ & $8(10.5 \%)$ & $6(22.2 \%)$ & 0.327 \\
\hline
\end{tabular}

Table 2. Surgery and post operative outcome parameters.

\begin{tabular}{|c|c|c|c|c|c|c|}
\hline & $\begin{array}{c}\text { Fractured Lesser } \\
\text { Trochanter } \\
\text { (A2.2\& A2.3) } \mathrm{N}=62\end{array}$ & $\begin{array}{l}\text { Reverse Oblique } \\
\text { (A3.1) } \mathrm{N}=63\end{array}$ & $\begin{array}{c}\text { Transverse } \\
\text { (A3.2) } \mathrm{N}=51\end{array}$ & $\begin{array}{l}\text { Comminuted } \\
\text { (A3.3) } \mathrm{N}=145\end{array}$ & $\begin{array}{l}\text { Subtrochanteric } \\
\qquad \mathrm{N}=65\end{array}$ & $P$ value \\
\hline \multicolumn{7}{|l|}{ IM Nail Type } \\
\hline Targon PF & $34(53.9 \%)$ & $49(77.8 \%)$ & $28(54.9 \%)$ & $96(66.2 \%)$ & $47(73.4 \%)$ & \\
\hline ATN & $29(46.1 \%)$ & $14(22.2 \%)$ & $23(45.1 \%)$ & $49(33.8 \%)$ & $17(26.6 \%)$ & 0.13 \\
\hline \multicolumn{7}{|l|}{ Nail length } \\
\hline Standard $(200-240 \mathrm{~mm})$ & $56(90.3 \%)$ & $58(92.1 \%)$ & $48(94.1 \%)$ & $109(75.2 \%)$ & $12(19.0 \%)$ & \\
\hline Long $(300-340 \mathrm{~mm})$ & $6(9.7 \%)$ & $5(7.9 \%)$ & $3(5.9 \%)$ & $36(24.8 \%)$ & $51(81.0 \%)$ & 0.0001 \\
\hline $\begin{array}{l}\text { Tip Apex distance } \leq 25 \mathrm{~mm} \\
(\mathrm{~N}=235)\end{array}$ & $28(66.7 \%)$ & $24(57.1 \%)$ & $29(81.2 \%)$ & $69(81.2 \%)$ & $20(66.7 \%)$ & 0.032 \\
\hline $\begin{array}{l}\text { Lag screw within "safe-zone" } \\
(\mathrm{N}=378)\end{array}$ & $53(85.5 \%)$ & $50(80.6 \%)$ & $42(87.5 \%)$ & $120(84.5 \%)$ & $49(76.6 \%)$ & 0.506 \\
\hline Reduction not achieved $(\mathrm{N}=383)$ & $6(9.8 \%)$ & $17(27.0 \%)$ & $10(19.6 \%)$ & $35(24.1 \%)$ & $12(19.0 \%)$ & 0.134 \\
\hline $\begin{array}{l}\text { Mobility points change from pre to } \\
1 \text { year post surgery }(\mathrm{N}=60)\end{array}$ & $1.66( \pm 1.23)$ & $1.77( \pm 1.30)$ & $2.14( \pm 1.06)$ & $1.90( \pm 1.33)$ & $0.75( \pm 1.35)$ & 0.174 \\
\hline $\begin{array}{l}\text { Walking } 1 \text { year after surgery } \\
(\mathrm{N}=77) 72 \%-93.5 \%\end{array}$ & $15(100 \%)$ & $8(88.9 \%)$ & $11(100 \%)$ & $25(89.3 \%)$ & $13(92.9 \%)$ & 0.566 \\
\hline
\end{tabular}


tures. The TAD was below $25 \mathrm{~mm}$ in only $57 \%-66 \%$ of lesser trochanter, reveres oblique and subtrochanteric fractures. This difference was found to be statistically significant ( $p$ value $=0.032$ ). However, $76 \%$ to $87 \%$ of the lag screws were placed within the head-neck interface "safe-zone". This difference was not found to be statistically significant ( $\mathrm{p}$ value $=0.506$ ). Reduction was not achieved in $7.6 \%$ patients. No statistically significant difference was found between fracture types $(\mathrm{p}$ value $=$ 0.386 ).

Seventy two patients $(93.5 \%)$ walked of 77 patients whose mobility status was recorded one year after surgery. Mobility aids used as recorded by the Parker score increased by a mean of 1.6 points $( \pm 1.3)$ one year after surgery. Sixty nine percent of the patients used a walking frame one year after surgery (Figure 1). No statistically significant difference was found in regards to mobility status between fracture types (Table 2).

One hundred and ninety one patients had either at least one year of follow-up with documented fracture union or any complication. Common complications included 14 $(7.3 \%)$ fractures that had cutout, 10 fractures $(5.2 \%)$ that had hardware failure and 7 fractures fixed with internal rotation above 30 degrees. Less common complications included deep wound infection, secondary loss of reduction, and fractures non-unions, with rates of $5(2.6 \%), 5$ $(2.6 \%)$ and $3(1.6 \%)$ fractures, respectively. No statistically significant difference was found between fracture types (Table 3).

Thirty two patients (16.8\%) of the aforementioned 191 patients had revision surgery. Common revision types included 14 (7.3\%) hardware removals, 7 (3.7\%) arthro-

Walking Aids Used

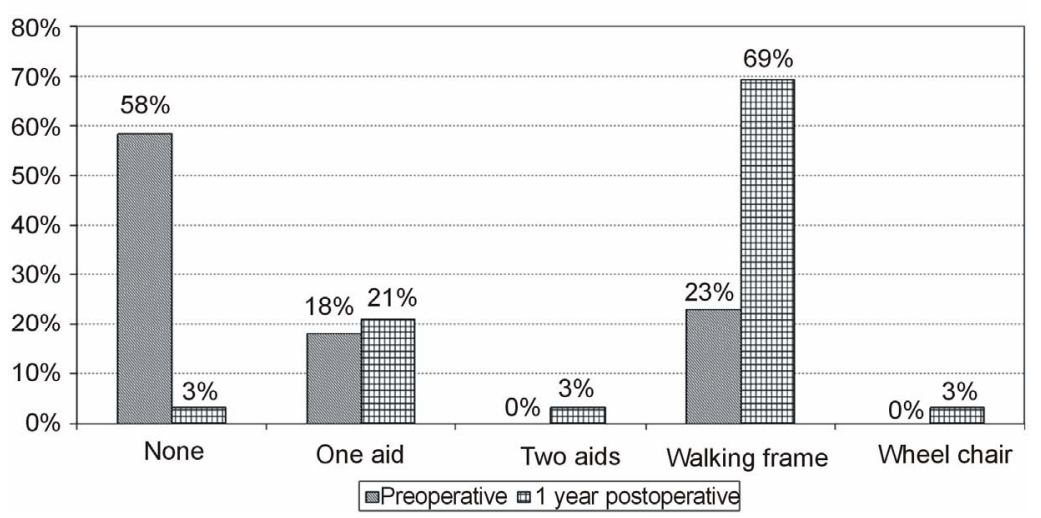

Figure 1. Walking aids score: where no aids, one aid, two aids, walking frame and wheel chair received a score of 1 - 5 in an ascending order. Mean increase in ambulation score from preoperative to 1 year after surgery was 1.63 points $( \pm 1.32)$. This difference was found to be statistically significant ( $p$ value $=\mathbf{0 . 0 0 0 1}$ ). No statistically significant difference was found between fracture patterns.

Table 3. Complications.

\begin{tabular}{|c|c|c|c|c|c|c|}
\hline Total $\mathrm{N}=191$ & $\begin{array}{c}\text { Fractured Lesser } \\
\text { Trochanter }(\mathrm{A} 2.2 \\
\& \mathrm{~A} 2.3) \mathrm{N}=34\end{array}$ & $\begin{array}{l}\text { Reverse Oblique } \\
(\text { A3.1) } \mathrm{N}=31\end{array}$ & $\begin{array}{c}\text { Transverse (A3.2) } \\
\mathrm{N}=23\end{array}$ & $\begin{array}{l}\text { Comminuted } \\
\text { (A3.3) } \mathrm{N}=78\end{array}$ & $\begin{array}{l}\text { Subtrochanteric } \\
\qquad \mathrm{N}=25\end{array}$ & $\begin{array}{c}P \\
\text { value }\end{array}$ \\
\hline Cut out -14 pts $(7.3 \%)$ & $3(8.8 \%)$ & $2(6.5 \%)$ & $4(17.4 \%)$ & $5(6.4 \%)$ & --- & 0.232 \\
\hline $\begin{array}{l}\text { Hardware failure }-10 \mathrm{pts} \\
\qquad(5.2 \%)\end{array}$ & $4(11.7 \%)$ & $2(6.5 \%)$ & --- & $4(5.2 \%)$ & --- & 0.278 \\
\hline Nonunion-3 pts $(1.6 \%)$ & $1(2.9 \%)$ & --- & $1(4.3 \%)$ & --- & $1(4.0 \%)$ & 0.16 \\
\hline $\begin{array}{l}\text { Deep wound infection } \\
\quad-5 \text { pts }(2.6 \%)\end{array}$ & --- & --- & --- & $4(5.1 \%)$ & $1(4.0 \%)$ & 0.508 \\
\hline $\begin{array}{l}\text { Secondary loss of } \\
\text { reduction } 5 \text { pts }(2.6 \%)\end{array}$ & $1(2.9 \%)$ & $1(3.2 \%)$ & --- & $1(1.3 \%)$ & $1(4.0 \%)$ & 0.674 \\
\hline $\begin{array}{c}\text { Internal rotation }-7 \mathrm{pts} \\
(3.7 \%)\end{array}$ & $3(8.8 \%)$ & $2(6.5 \%)$ & --- & $1(1.3 \%)$ & $1(4.0 \%)$ & 0.172 \\
\hline Other -3 pts $(1.5 \%)$ & $1(2.9 \%)$ & --- & --- & $1(1.3 \%)$ & $1(4.0 \%)$ & 0.564 \\
\hline $\begin{array}{c}\text { Total complications- }-47 \\
\text { pts }(24.6 \%)\end{array}$ & $13(38.2 \%)$ & $7(22.6 \%)$ & $5(21.7 \%)$ & $16(20.5 \%)$ & $6(24.0 \%)$ & 0.369 \\
\hline
\end{tabular}

Table 3 includes surgical complications and revision surgery. Other complications include one patient with pain that required revision, 1 patient with fracture at the lower end of the fixation device, and one patient with superior placement of the fixation device that required revision. No cases of deep vein thrombosis were reported. 
plasties and $5(2.6 \%)$ rotational corrections. No statistically significant difference was found between fracture types (Table 4).

One year and five years survival of the entire cohort were $79.6 \%$ (95\% CI of $75.1 \%-84.2 \%)$ and $48.9 \%(95 \%$ CI of $42.3 \%-56.4 \%$ ), respectively. Comparing survival between specific inter-trochanteric fractures, no statistically significant difference was found ( $\mathrm{p}$ value $=0.07$, Table 5). The fractures were grouped into high and low risk fracture types, according to survival. The low risk fracture types included reverse oblique fractures (31.A31) and comminuted fractures (31.A3-3). High risk fracture types included lesser trochanter unstable fractures (31.A2-2 and 31.A2-3), transverse fractures (31.A3-2) and subtrochanteric fractures (32 either A, B or C). One year and five years survival for the low risk fracture types were $86 \%$ (95\% CI $81.4 \%$ - 90.8\%) and $64.6 \%$ (95\% CI 57.4\% - 72.6\%), respectively. One year and five years survival for the high risk fracture types were $76.4 \%$ (95\% CI, 70.4\% - 82.9\%) and 49.3\% (95\% CI, 41.0\% $59.2 \%$ ). This difference was found to be statistically significant ( $\mathrm{p}$ value $=0.008$, Figure 2).

Multivariate analysis by the Proportional hazards model showed that the high risk fracture group was associated with higher mortality risk. Setting the low risk fracture group to have hazard ratio of one (as baseline) the hazard ratio for the high risk fracture group was 1.9 $(95 \% \mathrm{CI}=1.37-2.67)$. This difference was found to be statistically significant $(\mathrm{p}$ value $=0.0001)$. The hazard rate associated with age 60 - 80 was 17.7 (95\% CI $=4.3$ 73.1). The hazard rate associated with age above 80 years old was 19.6 (95\% CI $=4.7$ - 80.7). The hazard rate associated with each point of the ASA score was 1.152 $(95 \% \mathrm{CI}=0.88-1.5)$. This was not found to be statistically significant ( $\mathrm{p}$ value $=0.29$ ).

\section{Discussion}

In this manuscript, it was shown that survival rates differed between different types of unstable pertrochanteric fractures. These fractures could be divided into low and high risk fracture types. The low risk group includes: reverse oblique and comminuted fractures. The high risk fracture types include: lesser trochanter, transverse and subtrochanteric fractures. No difference in clinical or epidemiologic characteristics was found in order to explain the difference in survival. No difference was found in complication and revision rates that could also elucidate the survival difference.

In previous works, other authors focused mainly on

Table 4. Revisions.

\begin{tabular}{|c|c|c|c|c|c|c|}
\hline Total $\mathrm{N}=191 \mathrm{pts}$ & $\begin{array}{c}\text { Fractured Lesser } \\
\text { Trochanter } \\
(\mathrm{A} 2.2 \& \mathrm{~A} 2.3) \mathrm{N}=34\end{array}$ & $\begin{array}{l}\text { Reverse Oblique } \\
\text { (A3.1) } \mathrm{N}=31\end{array}$ & $\begin{array}{c}\text { Transverse } \\
\text { (A3.2) } \mathrm{N}=23\end{array}$ & $\begin{array}{c}\text { Comminuted } \\
\text { (A3.3) } \mathrm{N}=78\end{array}$ & $\begin{array}{l}\text { Subtrochanteric } \\
\qquad N=25\end{array}$ & $P$ value \\
\hline $\begin{array}{l}\text { Total Hip replacement } \\
-3 \text { pts }(1.6 \%)\end{array}$ & $2(5.9 \%)$ & --- & $1(4.3 \%)$ & --- & --- & 0.086 \\
\hline $\begin{array}{c}\text { Hemiarthroplasty }-4 \\
\text { pts }(2.1 \%)\end{array}$ & --- & --- & --- & $4(5.1 \%)$ & --- & 0.441 \\
\hline $\begin{array}{c}\text { Exchange nail }-4 \mathrm{pts} \\
(2.1 \%)\end{array}$ & --- & --- & $1(4.3 \%)$ & $2(2.6 \%)$ & $1(4.0 \%)$ & 0.533 \\
\hline $\begin{array}{c}\text { Hardware removal-11 } \\
\text { pts }(5.7 \%)\end{array}$ & $3(8.8 \%)$ & $3(9.4 \%)$ & $1(4.3 \%)$ & $4(5.1 \%)$ & --- & 0.552 \\
\hline $\begin{array}{c}\text { Nail removal and } \\
\text { plating }-3 \text { pts }(1.6 \%)\end{array}$ & --- & --- & $2(8.7 \%)$ & --- & $1(4.0 \%)$ & 0.018 \\
\hline $\begin{array}{c}\text { Rotation correction }-5 \\
\text { pts }(2.6 \%)\end{array}$ & $2(5.9 \%)$ & $1(3.2 \%)$ & --- & $1(1.3 \%)$ & $1(4.0 \%)$ & 0.455 \\
\hline $\begin{array}{l}\text { Soft tissue revision due } \\
\text { to infection } 1 \mathrm{pt}(0.5 \%)\end{array}$ & --- & --- & --- & $1(1.3 \%)$ & --- & 1.00 \\
\hline $\begin{array}{c}\text { Total revisions-32 pts } \\
(16.8 \%)\end{array}$ & $7(20.6 \%)$ & $4(12.9 \%)$ & $5(21.7 \%)$ & $12(15.4 \%)$ & $4(16.0 \%)$ & 0.876 \\
\hline
\end{tabular}

Table 5. Survival estimates (95\% confidence intervals).

\begin{tabular}{|c|c|c|c|c|c|}
\hline Total $=386$ patients & $\begin{array}{c}\text { Fractured Lesser } \\
\text { Trochanter } \\
(\mathrm{A} 2.2 \& \mathrm{~A} 2.3) \mathrm{N}=62\end{array}$ & $\begin{array}{l}\text { Reverse Oblique (A3.1) } \\
\qquad N=63\end{array}$ & $\begin{array}{c}\text { Transverse (A3.2) } \\
\qquad \mathrm{N}=51\end{array}$ & $\begin{array}{l}\text { Comminuted (A3.3) } \\
\qquad \mathrm{N}=145\end{array}$ & Subtrochanteric $\mathrm{N}=65$ \\
\hline Six months & $95.2 \%(90 \%-100 \%)$ & $93.5 \%(87.6 \%-99.9 \%)$ & $88.2 \%(79.8 \%-97.5 \%)$ & $91 \%(86.5 \%-95.8 \%)$ & $80 \%(70.8 \%-90.3 \%)$ \\
\hline One year & $77.4 \%(67.6 \%-88.5 \%)$ & $90.3 \%(83.3 \%-98 \%)$ & $74.5 \%(63.4 \%-87.5 \%)$ & $84.1 \%(78.4 \%-90.3 \%)$ & $76.9 \%(67.3 \%-87.9 \%)$ \\
\hline Five years & $55.7 \%(42 \%-73.9 \%)$ & $63.2 \%(50.9 \%-78.4 \%)$ & $37.9 \%(22.8 \%-62.8 \%)$ & $64.5 \%(56 \%-74.3 \%)$ & $50.5 \%(38.5 \%-66.3 \%)$ \\
\hline
\end{tabular}

$\mathrm{P}$ value for survival curves comparing all the fracture types $=0.07$. 


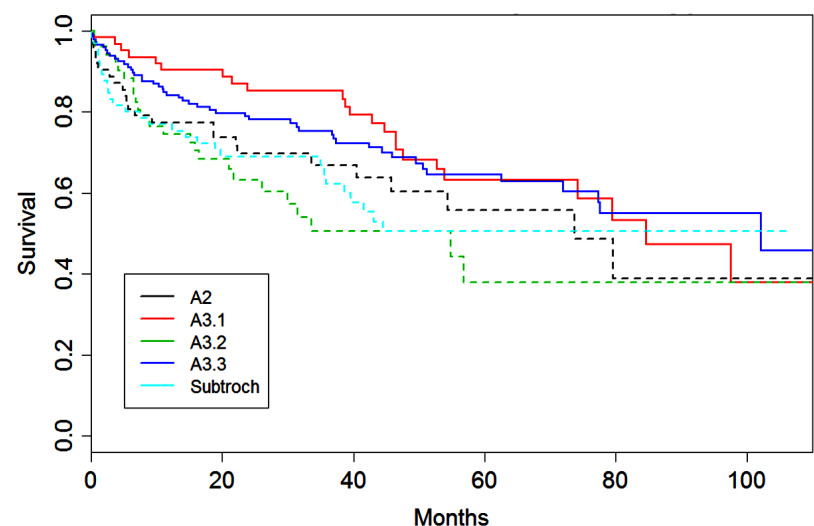

(a)

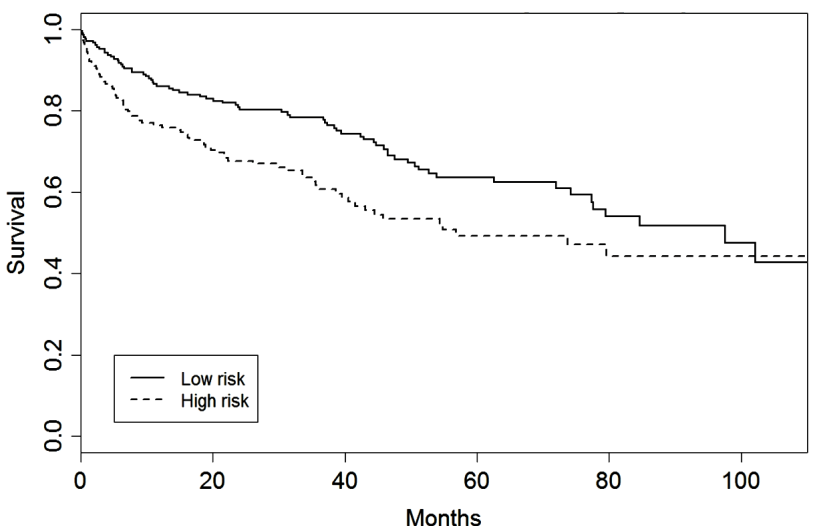

(b)

Figure 2. Kaplan-Meier survival curves. Low risk fracture types include AO types A3.1 (reverse oblique), A3.3 (Comminuted). High risk fracture type include AO types A2 (lesser trochaner fracture), A3.2 (transverse), and subtrochanteric fractures. The difference in survival was found to be statistically significant ( $p$ value $=\mathbf{0 . 0 0 8}$ ). (a) Kaplan Meier survival curves after fixation—by fracture type. (b) Kaplan Meier survival curves after fixation—by risk group.

describing series of specific unstable fractures, without comparing between them. Reported complications of unstable pertrochanteric fractures fixation included cutouts $(4 \%-20 \%)$, femoral shaft fractures $(0 \%-10 \%)$ and nonunions $(1 \%-2 \%)$ [4]. Subtrochanteric fracture fixation had shown similar results $[21,23]$. These complication rates are comparable to the rates presented in this study. In our work, no statistically significant difference was found between fracture types in reviewing postoperative complications.

Some authors studied factors influencing the mortality of patients after internal fixation of pertrochanteric fractures. Forte et al. have examined the ninety day mortality in patients treated by internal fixation of pertrochanteric fracture. They have shown that patients treated at a low volume versus high volume institutes had mortality rates for ninety days of $24.4 \%$ and $12.9 \%$, respectively [24]. These survival rates are comparable to the survival presented in this study. Donegan et al. has shown that higher ASA was associated with higher in hospital mortality rates. This was due to higher medical complications in patients with higher ASA scores [25]. In our study no clinically significant difference in ASA score was found between fracture types.

We found the lack of successful reduction in $7.6 \%$ of patients, with no statistically significant difference among fracture types. This result does not indicate as to the difficulty in achieving reduction, only the final results. This finding is especially important since the reduction quality is considered by many to be one of the major criteria in preventing further complications [26-28]. The TAD was found to differ between fracture types. This did not influence the failure rates between fracture types. This finding is in contradiction to other authors who have shown that TAD above 25 was associated with higher rates of cutouts $[26,29]$.
Recently, we reported a new radiographic measure for correcting lag screw position. Using polar to Cartesian coordinates transformation, we were able to devise a femur head-neck interface "safe zone" for the center of the lag screw. In short, this safe zone is the second quarter (from the bottom) of the head-neck interface line. In this dataset $76 \%$ to $87 \%$ of the lag screws were found within the head-neck "safe-zone". This parameter did not differ among fracture types. This finding can explain why there were no differences in the rates of cutout between different fracture patterns.

The main drawback of the article is the fact that it is retrospective. As such, some data were not available, either not accessible or it was not recorded to begin with. However, the retrospective nature of the analysis enabled us to include maximum patients in our study. Further, the main result of the study, namely survival rates, was extracted from the national databases which are independent from the study design.

We believe that our results offer some new conclusions regarding unstable pertrochanteric fractures. We found that unstable pertrochanteric fractures are similar in demographics and surgery outcome. Also their complications and revision rates are similar. However, these fractures differ in survival of patients after surgery.

\section{Acknowledgements}

This study was funded by the Talpiot medical leadership program of the Chaim Sheba, Tel-Hashomer, Hospital.

\section{REFERENCES}

[1] S. Cummings, S. M. Rubin and D. Black, "The Future of Hip Fractures in the United States: Numbers, Costs, and Potential Effects of Postmenopausal Estrogen," Clinical Orthopedics and Related Research, Vol. 252, 1990, pp. 
$163-166$.

[2] K. Koval, G. B. Aharonoff, A. S. Rokito, T. Lyon and J. D. Zuckerman, "Patients with Femoral Neck and Intertrochanteric Fractures: Are They the Same? Clinical Orthopedics and Related Research, Vol. 330, 1996, pp. 166172.

http://dx.doi.org/10.1097/00003086-199609000-00020

[3] Fracture and Dislocation Classification Compendium, "Orthopaedic Trauma Association Classification, Database and Outcomes Committee," Journal of Orthopedic Trauma, Vol. 20, No. 10 (S1), 2007, pp. 31-42.

[4] D. Lindskog and M. R. Baumgaertner, "Unstable Intertrochanteric Hip Fractures in the Elderly," Journal of the American Academy of Orthopaedic Surgeons, Vol. 12, No. 3, 2004, pp. 189-190.

[5] M. Parker and H. H. Handoll, "Gamma and Other Cephalocondylic Intramedullary Nails versus Extramedullary Implants for Extracapsular Hip Fractures in Adults," Cochrane Database Systematic Review, Vol. 3, 2008, p. CD93.

[6] C. Sadowski, A. Lübbeke, M. Saudan, N. Riand, R. Stern and P. Hoffmeyer, "Treatment of Reverse Oblique and Transverse Intertrochanteric Fractures with Use of an Intramedullary Nail or a $95^{\circ}$ Screw-Plate: A Prospective, Randomized Study," Journal of Bone and Joint Surgery (Am), Vol. 84, No. 3, 2002, pp. 372-381.

[7] S. Bridle, A. D. Patel, M. Bircher and P. T. Calvert, "Fixation of Intertrochanteric Fractures of the Femur, a Randomized Prospective Comparison of the Gamma Nail and the Dynamic Hip Screw," Journal of Bone and Joint Surgery (Br), Vol. 73-B, No. 2, 1991, pp. 330-334.

[8] B. Giraud, E. Dehoux, N. Jovenin, K. Madi, A. Harisboure, G. Usandizaga, et al., "Pertrochanteric Fractures: A Randomized Prospective Study Comparing Dynamic Screw Plate and Intramedullary fixation," Revue de Chirurgie Orthopedique et Reparatrice de l'Appareil Moteur, Vol. 91, No. 8, 2005, pp. 732-736. http://dx.doi.org/10.1016/S0035-1040(05)84484-8

[9] D. Hardy, P. Y. Descamps, P. Krallis, L. Fabeck, P. Smets, C. L. Bertens and P. E. Delince, "Use of an Intramedullary Hip-Screw Compared with a Compression HipScrew with a Plate for Intertrochanteric Femoral Fractures: A Prospective, Randomized Study of One Hundred Patients," Journal of Bone and Joint Surgery (Am), Vol. 80, No. 5, 1998, pp. 618-630.

[10] K. Leung, W. S. So, W. Y. Shen and P. W. Hui, "Gamma Nails and Dynamic Hip Screws for Peritrochanteric Fractures: A Randomized Prospective Study in Elderly Patients," Journal of Bone and Joint Surgery (Am), Vol. 74-B, No. 3, 1992, pp. 345-351.

[11] J. Madsen, L. Næss, A. K. Aune, A. Alho, A. Ekeland and K. Strømsøe, "Dynamic Hip Screw with Trochanteric Stabilizing Plate in the Treatment of Unstable Proximal Femoral Fractures: A Comparative Study with the Gamma Nail and Compression Hip Screw," Journal of Orthopedic Trauma, Vol. 12, No. 4, 1998, pp. 241-248. http://dx.doi.org/10.1097/00005131-199805000-00005

[12] C. Mainds and R. J. Newman, "Implant Failures in Patients with Proximal Fractures of the Femur Treated with a Sliding Screw Device," Injury, Vol. 20, No. 2, 1989, pp.
98-109. http://dx.doi.org/10.1016/0020-1383(89)90151-4

[13] E. Osnes, C. M. Lofthus, J A. Falch, et al., "More PostOperative Femoral Fractures with the Gamma Nail than the Sliding Screw Plate in the Treatment of Trochanteric Fractures," Acta Orthopedica Scandinavica, Vol. 72, No. 3, 2001, pp. 252-256. http://dx.doi.org/10.1080/00016470152846574

[14] J. Pajarinen, J. Lindahl, O. Michelsson, V. Savolainen and E. Hirvensalo, "Pertrochanteric Femoral Fractures Treated with a Dynamic Hip Screw or a Proximal Femoral Nail; a Randomised Study Comparing Postoperative Rehabilitation," Journal of Bone and Joint Surgery $(\mathrm{Br})$, Vol. 87, No. 1, 2005, pp. 76-81.

[15] S. Papasimos, C. M. Koutsojannis, A. Panagopoulos, P. Megas and E. Lambiris, "A Randomised Comparison of AMBI, TGN and PFN for Treatment of Unstable Trochanteric Fractures," Archives of Orthopaedic and Trauma Surgery, Vol. 125, No. 7, 2005, pp. 462-468. http://dx.doi.org/10.1007/s00402-005-0021-5

[16] P. Radford, M. Needoff and J. K. Webb, "A Prospective Randomized Comparison of the Dynamic Hip Screw and the Gamma Locking Nail," Journal of Bone and Joint Surgery (Br), Vol. 75-B, No. 5, 1993, pp. 789-793.

[17] C. Rogmark, L. Flensburg and H. Fredin, "Undisplaced Femoral Neck Fractures-No Problems? A Consecutive Study of 224 Patients Treated with Internal Fixation," Injury, Vol. 40, No. 3, 2009, pp. 274-276.

[18] M. Saudan, A. Lubbeke, C. Sadowski, N. Riand, R. Stern and P. Hoffmeyer, "Pertrochanteric Fractures: Is There an Advantage to an Intramedullary Nail? A Randomized, Prospective Study of 206 Patients Comparing the Dynamic Hip Screw and Proximal Femoral Nail," Journal of Orthopaedic Trauma, Vol. 16, No. 6, 2002, pp. 386-393. http://dx.doi.org/10.1097/00005131-200207000-00004

[19] I. Schipper, E. W. Steyerberg, R. M. Castelein, F. H. W. M. van der Heijden, P. T. den Hoed, A. J. H. Kerver and A. B. van Vugt, "Treatment of Unstable Trochanteric Fractures: Randomised Comparison of the Gamma Nail and the Proximal Femural Nail," Journal of Bone and Joint Surgery (Br), Vol. 86-B, No. 1, 2004, pp. 86-94.

[20] R. Simmermacher, A. M. Bosch and C. H. Van der Werken, "The AO/ASIF-Proximal Femoral Nail (PFN): A New Device for the Treatment of Unstable Proximal Femur Fractures," Injury, Vol. 30, No. 5, 1990, pp. 327-332. http://dx.doi.org/10.1016/S0020-1383(99)00091-1

[21] D. Lundy, "Subtrochanteric Femoral Fractures," Journal of the American Academy of Orthopaedic Surgeons, Vol. 15, No. 11, 2007, pp. 663-671.

[22] A. L. F. Afsari, E. Lindvall, A. Infante, H. C. Sagi and G. J. Haidukewych, "Clamp-Assisted Reduction of High Subtrochanteric Fractures of the Femur," Journal of Bone and Joint Surgery (Am), Vol. 92, No. S1 (Part 2), 2009, pp. 1913-1918. http://dx.doi.org/10.2106/JBJS.H.01563

[23] M. Baumgaertner, S. L. Curtin, D. M. Lindskog and J. M. Keggi, "The Value of the Tip-Apex Distance in Predicting Failure of Fixation of Peritrochanteric Fractures of the Hip," Journal of Bone and Joint Surgery (Am), Vol. 77, No. 7, 1995, pp. 1058-1064.

[24] M. Forte, B. A. Virnig, M. F. Swiontkowski, M. Bhandari, 
R. Feldman, L. E. Eberly and R. L. Kane, "Ninety-Day Mortality after Intertrochanteric Hip Fracture: Provider Volume Matter?" Journal of Bone and Joint Surgery (Am), Vol. 92, No. 4, 2010, pp. 799-806. http://dx.doi.org/10.2106/JBJS.H.01204

[25] D. J. Donegan, A. N. Gay, K. Baldwin, E. E. Morales, J. L. Esterhai and S. Mehta, "Use of Medical Comorbidities to Predict Complications after Hip Fracture Surgery in the Elderly," Journal of Bone and Joint Surgery (Am), Vol. 92, No. 4, 2010, pp. 807-813. http://dx.doi.org/10.2106/JBJS.I.00571

[26] T. Barton, R. Gleeson, C. Topliss, R. Greenwood, W. J. Harries and T. J. S. Chesser, "A Comparison of the Long Gamma Nail with the Sliding Hip Screw for the Treatment of AO/OTA 31-A2 Fractures of the Proximal Part of the Femur: A Prospective Randomized Trial," Journal of Bone and Joint Surgery (Am), Vol. 92, No. 4, 2010, pp.
792-798. http://dx.doi.org/10.2106/JBJS.I.00508

[27] T. Davis, J. L. Sher, A. Horsman, M. Simpson, B. B. Porter and R. G. Checketts, "Intertrochanteric Femoral Fractures-Mechanical Failure after Intrenal Fixation," Journal of Bone and Joint Surgery $(\mathrm{Br})$, Vol. 72-B, No. 1, 1990, pp. 26-31.

[28] S. Larsson, S. Friberg and L. Hansson, "Trochanteric Fractures, Influence of Reduction and Implant Position on Impaction and Complications," Clinical Orthopedics and Related Research, Vol. 259, 1990, pp. 130-139.

[29] M. Güvena, U. Yavuzb, B. Kadıogluc, B. Akmand, V. K1lincoglue, K. Ünayc and F. Altıntas, "Importance of Screw Position in Intertrochanteric Femoral Fractures Treated by Dynamic Hip Screw," Orthopaedics \& Traumatology: Surgery \& Research, Vol. 96, No. 1, 2010, pp. 21-27. 